MISCELLANEOUS PAPER NO. 4-854

\title{
CONCEPTS FOR VEHICLES FOR OFF-ROAD USE IN REMOTE AREAS \\ by
}
A. A. Rula
D. R. Freitag
S. J. Knight

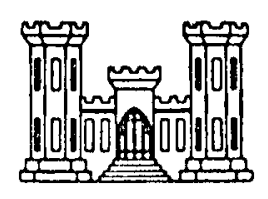

November 1966

U. S. Army Engineer Waterways Experiment Station CORPS OF ENGINEERS

Vicksburg, Mississippi 
TA?

(1) $20.25+1$

No.

$\cos 0$

FOREWORD

This paper discusses a stuay conducted at the U. S. Army Engineer Waterways Experiment Station (WFS) under the sponsorship and guidance of the Directorate of Resenrch and Development, U. S. Army Matcriel Command.

The study was accomplished under the general guidance of Mr. R. R. Philippe, AMC, assisted by Messrs. R. C. Kerr and P. F. Carlton, AMC: Mr. M. V. Kreipke, Army Research Office, Mr. J. P. Sale, Office, Chief of Engineers; and Mr. R. A. Liston, Land Locomotion Laboratory, U. S. Army Tank-Automotive Center. The work was performed under the supervision of Messrs. W. J. Turmbull, Technical Assistant for Soils and Environmental Engineering, and W. G. Shockley, Chief of the Mobility and Environmental Division, WES, by a group of specialist engineers and geologists who devoted full time to the study during the period 21-25 September 1964 .

This paper was prepared by Messrs. A. A. Rula, D. R. Freitag, and S. J. Knight for presentation at the Society of Automotive Ingineers, Inc. (SAE) Automotive Engineering Congress and Exposition in Detroit, Mich., 5-13 January 1967. Clearance for presentation at the meeting and for publication by SAE was granted by the WES Local Publications Review Board. 
by

A. A. Rula, ${ }^{1}$ D. R. Freitag, ${ }^{2}$ and S. J. Knight ${ }^{3}$

ABSTRACT

A group of specialists was assembled at the U. S. Army Engineer Waterways Experiment Staion (WES) to consider quantitatively the various elements of the entire vehicle mobility problem and to suggest an approach for achieving a substantial degree of solution. One specific purpose of the meeting, and the one that is the subject of this paper, was to design a number of vehicles capable of operating in remote areas of the world where extremely soft soil conditions predominate.

Methods of design based on research studies at the WES and at the Land Locomotion Laboratory (LII), U. S. Army Tank-Automotive Center, were employed to specify tractive component characteristics that would yield the desired soft soil performance. The final concepts that were evolved reflect chiefly the soft soil requirements, but other factors such as obstacle performance were also kept in mind. This paper describes the application of the design methods and presents the two wheeled-vehicle concepts and the one tracked-vehicle concept that were evolved to satisfy the basic assumptions.

I Chief, Vehicle Studies Branch, Mobility and Environmental Division, U. S. Army' Engineer Waterways Experiment Station, Vicksburg, Mississippi.

2 Chief, Mobility Research Branch, Mobility and Environmental Division, U. S. Army Engineer Waterways Experiment Station, Vicksburg, Mississippi.

3 Assistant Chief, Mobility and Environmental Division, U. S. Army Engineer Waterways Experiment Station, Vicksburg, Mississippi. 
In response to views expressed by Gen. Frank S. Besson, Jr., Commanding General, U. S. Army Materiel Command (AMC), a group of mobility, soil, and terrain evaluation specialists of AMC, the U. S. Army Corps of Engineers, and associated consultants assembled at the U. S. Army Engineer Waterways Experiment Station (WES) to consider the various quantitative elements of the off-road ground mobility problem and to suggest an approach for achieving a substantial degree of solution (1)*. One specific purpose of the meeting, and the subject of this paper, was to design vehicles capable of operating in extremely soft soil conditions.

Methods of design based on research studies at the WES and at the Land Locomotion Laboratory (ILL), U. S. Army Tank-Automotive Center, were employed to specify vehicle traction components that would yield the desired soft soil performance. The final configurations of the two wheeled-vehicle concepts and the one tracked-vehicle concept that were evolved reflect chiefly the soft soil requirements, but other factors such as obstacle performance were also considered in the design.

\section{DESIGN REQUIREMENTS}

The vehicle requirements specified were: (a) ability to travel in a straight line on a soil strength of 25 rating cone index (RCI)** for 50 passes and on a 10 RCI for a single pass with maneuvering, (b) ability to

\footnotetext{
* Numbers in parentheses designate References at end of paper.

* RCI is the remolded soil strength effective under vehicle traffic and is numerically equal to the product of the cone index and the remolding index for the same soil layer.
} 
maintain a speed of $5 \mathrm{mph}$ in the minimum soil strength, (c) ability to transport a pay load of $5,000 \mathrm{lb}$, (d) maximum vehicle gross weight of 15,000 Ib, (e) provision of an unbroken cargo space consistent with current military packaging techniques, and ( $f$ ) development of a design that demands a minimum of new components. Minimum power of $15 \mathrm{hp}$ per ton was established, unless the requirement to develop $5 \mathrm{mph}$ at the design soil strength demanded additional power.

The criteria for obstacle performance, identified as general design considerations, included: (a) provisions for maximum approach and departure angles, (b) reduction of breakover angles to a minimum, (c) provision for maximum conformity to rough-ground profiles by means of articulation in pitch, roll, and yaw, (d) inclusion of suspension systems to develop maximum off-road speed and to eliminate excessive "loping" during highway operation, (e) ability to negotiate a 3-ft-high obstacle, and ( $f$ ) ability to ford a 4-ft-deep stream.

SYSTEMS USED TO MEET DESIGN REQUIREMENTS

The WES Army Mobility Research Branch (AMRB) mobility index system was used to determine the design of both wheeled and tracked vehicles capable of completing 50 straight-line passes on a soil with an RCI of 25 . The AMRB numeric system was employed to design wheeled vehicles (only) for onepass maneuvering on a soil with an RCI of $\%$ The III soil value system was used to determine both wheeled and tracked designs on the basis of maneuvering on a soil strength of 7 RCI. A value of 7 RCI was selected (instead of the 10 RCI specified in the design requirements) in order to inject a factor of safety. The three systems gave similar, but not identical, wheel 
and track dimensions for the specified conditions. The final designs were conservative, i.e. the wheels and tracks selected were slightly larger than those indicated to be necessary by calculation procedure, ground clearance, or obstacle consideration.

AMRB MOBILITY INDEX SYSTEM

The two empirical formulas developed from numerous vehicle tests conducted in fine-grained soil for wheeled and tracked vehicles were used to compute the minimum, soil strength required for a vehicle to travel 50 passes in the same path (2). The formulas are generally similar. Both rely heavily on a contact pressure factor and both are influenced to a lesser extent by such factors as gross weight, clearance, engine horsepower, and transmission type. The formulas yield a "mobility index" (MI) which, in turn, is related by means of a curve (fig. 1) to the vehicle cone index (VCI), the minimum soil strength in terms of RCI that will allow a vehicle to complete 50 passes.

WHEELED VEHICIES - The MI formula used for wheeled vehicles* (allwheel drive) operating in fine-grained soils is:

$$
\text { MI }=\left(\begin{array}{l}
\begin{array}{l}
\text { contact } \\
\text { pressure } \times \text { weight } \\
\text { factor }
\end{array} \\
\begin{array}{l}
\text { fire } \\
\text { factor }
\end{array} \times \begin{array}{l}
\text { grouser } \\
\text { factor }
\end{array} \text { foactor } \\
\text { factor }
\end{array}\right) \times \begin{aligned}
& \text { flearance } \\
& \text { factor } \\
& \text { factor }
\end{aligned} \times \begin{aligned}
& \text { transmission } \\
& \text { factor }
\end{aligned}
$$

where

$$
\begin{aligned}
& \text { contact }
\end{aligned}
$$

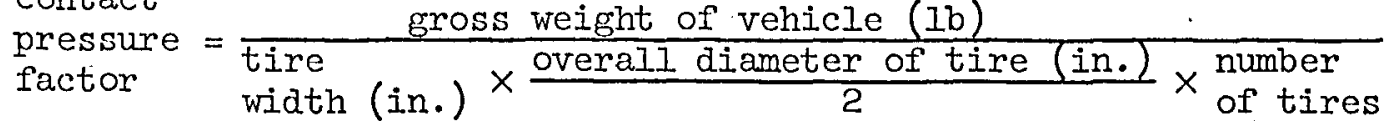

* The mobility index formula used herein differs slightly from that given in the reference. 


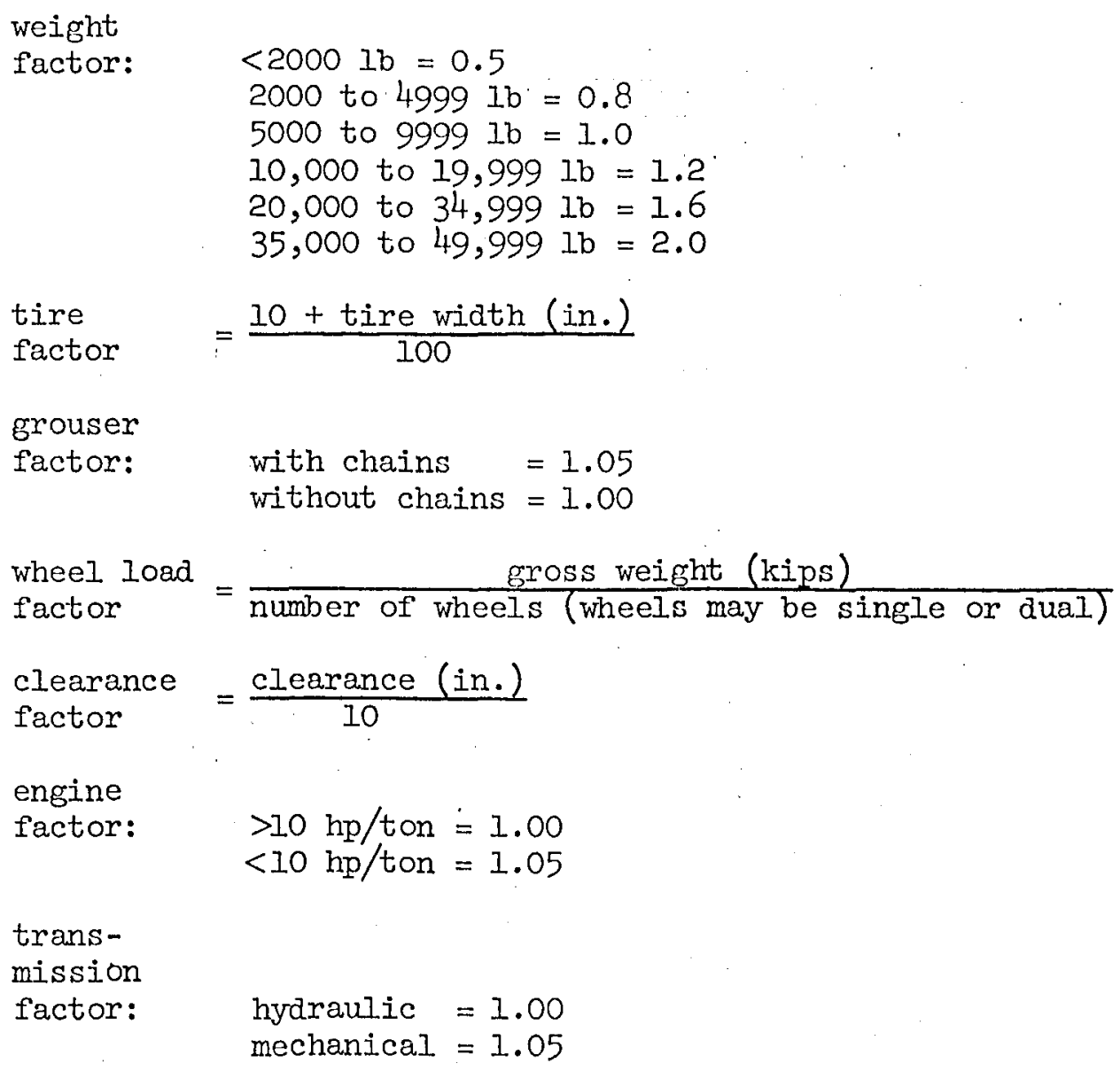

In applying the wheeled-vehicle formula, the following assumptions were made: gross weight is $15,000 \mathrm{lb}$; no chains or other traction devices are employed; wheels are single (not dual); the engine horsepower is greater than 10 per ton; clearance is equal to outside diameter of tire divided by 3 ; and the transmission is a hydraulic type.

A width of tire (b) was assumed, and the overall diameter (d) required to yield a value of $M I=9$ (corresponds to VCI $=25$, fig. 1 ) was then computed. Since the clearance factor depended on a value of $d$, application of the formula required a certain amount of trial and error in solving for d. A sample calculation is shown on the following page. Results of the calculations for a range of tire widths are summarized in fig. 2; 
shown are tire width versus overall tire diameter requirements for $4 \times 4$, $6 \times 6,8 \times 8$, and $10 \times 10$ wheel concepts.

Vehicle: $6 \times 6$; weight $=15,0001 \mathrm{~b}$

Tire: width $=25$ in.; overall diameter $=76$ in.

$$
M I=\left[\frac{(1) \times(2)}{(3) \times(4)}+(5)-(6)\right] \times(7) \times(8)
$$

where
(1) contact
$\begin{aligned} & \text { pressure } \\ & \text { factor }\end{aligned}:=\frac{15,000}{25 \times \frac{76}{2} \times 6}=2.63$
(2) weight
factor
$=1.20$
(3) tire factor $=\frac{10+25}{100}=0.35$
(4) grouser
factor
$=1.00$
(5) wheel load
factor
$=\frac{15}{6}=2.50$
(6) clearance
$=\frac{76 / 3}{10}=2.53$
(7) engine
$=1.00$
(8) $\begin{aligned} & \text { transmission } \\ & \text { factor }\end{aligned}=1.00$

$$
\text { MI }=\left(\frac{2.63 \times 1.20}{0.35 \times 1.00}+2.50-2.53\right) \times 1.00 \times 1.00=9.0
$$

Therefore, from fig. I: VCI $=25$

TRACKED VEHICIES - The MI formula used for tracked vehicles operating in fine-grained soils is: 


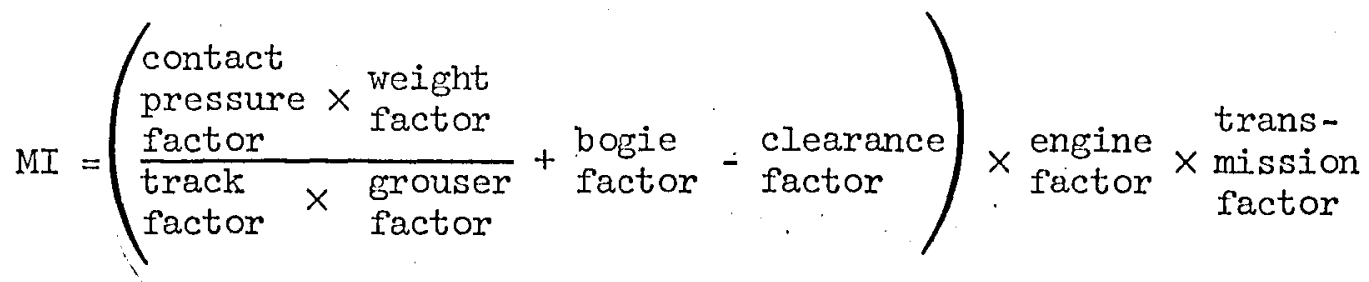

where

$$
\begin{aligned}
& \text { contact } \\
& \text { pressure } \\
& \text { factor } \\
& =\frac{\text { gross weight of vehicle (Ib) }}{\text { area of tracks in contact with ground (sq in.) }} \\
& \text { weight } \\
& \text { factor: } \\
& <50,000 \mathrm{lb}=1.0 \\
& 50,000 \text { to } 69,999 \mathrm{lb}=1.2 \\
& 70,000 \text { to } 99,999 \mathrm{Ib}=1.4 \\
& >100,000 \mathrm{lb}=1.8 \\
& \begin{array}{l}
\text { track } \\
\text { factor }
\end{array}=\frac{\text { track width (in.) }}{100} \\
& \text { grouser } \\
& \text { factor: } \quad<1.5 \text { in. high }=1.0 \\
& >1.5 \text { in. high }=1.1
\end{aligned}
$$

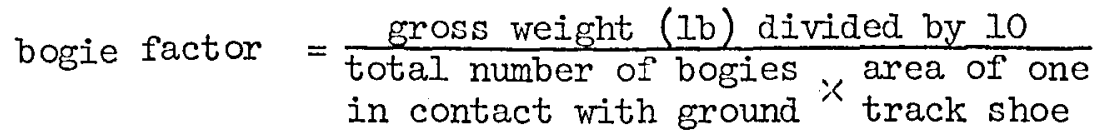

$$
\begin{aligned}
& \begin{array}{l}
\text { clearance } \\
\text { factor }
\end{array}=\frac{\text { clearance (in.) }}{10} \\
& \text { engine } \\
& \text { factor: } \quad>10 \mathrm{hp} / \text { ton }=1.00 \\
& <10 \mathrm{hp} / \text { ton }=1.05 \\
& \text { transmission } \\
& \text { factor: hydraulic }=1.00 \\
& \text { mechanical }=1.05
\end{aligned}
$$

The assumptions made in applying the tracked-vehicle formula were as follows: gross weight is $15,000 \mathrm{lb}$; grousers on the tracks are less than 1 in. high; number of bogie wheels per side equals $\frac{\text { track length }}{30}+1$; clearance is 20 in.; engine horsepower is greater than 10 per ton; and transmission is a hydraulic type. No special credit was given in this calculation for the advantages accruing from steering by articulation. 
In applying the results to articulated vehicles, the required track length was taken as the total length for the two tracks (one on each unit) on a side.

A width (b) was assumed, and the length of track ( $l$ ) required to yield a value of $M I=9$ was then computed. Since the bogie factor depends on the value of $\ell$, direct use of the formula again required a certain amount of trial and error in solving for $\ell$. Fig. 3 shows a plot of $b$ versus $\&$ to provide a VCI of 25 .

AMRB NUMERIC SYSTEM FOR WHEELED VEHICLES

The results of tests in the AMRB test facilities (3) with single tires ranging from 14 to 41 in. in diameter, on soft clay soil varying in strength from 10 to 60 cone index, indicate that the performance of these tires, in terms of net drawbar pull at any given slip $\left(\mathrm{P}_{\text {slip }}\right)$ and towed force $\left(P_{T}\right)$ developed on the first pass, can be related to a numeric involving wheel load (W), cone index (CI), tire width (b), tire diameter (d), and deflection $(\Delta)$. These relations are shown graphically in fig. 4.

Certain assumptions were made in applying the AMRB numeric. First, the wheel load was assumed equal to the gross weight divided by the number of wheels. Vehicle concepts with 4, 6, 8, and 10 wheels were considered. Second, it was assumed that all tires operated at a deflection of 25 percent of section height. Third, the vehicle concepts were assumed to operate at 20 percent slip, at which approximately 90 percent of the maximum drawbar pull is developed by wheeled vehicles operating on soft soil conditions. In the design of wheel configurations, the "no-maneuver" and "maneuver" situations were considered separately. 
NO-MANEUVER CASE - The first step in applying the numeric to the design problem in the no-maneuver case was to find from fig. 4 the finite value $\left(V_{I}\right)$ of the AMRB numeric $\frac{W}{C I b d \Delta^{0.5}}$ when $P_{20} / W=0$, i.e. when the vehicle is barely able to propel itself. Next, a value for bd was found from the equation, $b d=\frac{W}{C I \Delta^{0.5} V_{I}}=V_{2}$. Finally, the hyperbola bd $=V_{2}$ was plotted to represent an infinite number of combinations of $b$ and $d$ (as shown in fig. 5) that satisfy the specified conditions. This procedure is illustrated in the following example for the 15,000-1b, $4 \times 4$ concept with tires at a deflection of 25 percent operating on a soil with an RCI of 7 . Example: From fig. 4 at $P_{20} / W=0$, read a value of

$$
\begin{aligned}
\frac{W}{\mathrm{CIbd} \Delta} & =0.41=V_{1} \\
\quad b d & =\frac{15,000 / 4}{7 \times(0.25)^{0.5} \times 0.41}=2610
\end{aligned}
$$

The equation $\mathrm{bd}=2610$ was then solved for several assumed values of $\mathrm{b}$, and the curve marked $4 \times 4$ in fig. 5 was constructed.

MANEUVER CASE - To allow for maneuvering on a soil with a CI of 7 , it was necessary to compute a larger bd combination which would represent an ability to develop a finite net drawbar pull (in a straight line) equal to the additional forces considered to be required for maneuvering: The maneuver forces were assumed to be equal to the motion resistance for a $4 \times 4$, one-half the motion resistance for a $6 \times 6$, one-quarter that for an $8 \times 8$, and zero for a $10 \times 10$ wheeled vehicle. The motion resistance, in turn, was assumed to be equal to the force necessary to tow the vehicle in a 
straight-line path $\left(\mathrm{P}_{\mathrm{T}}\right)$. The procedure used for determining bd values for maneuvering for a $4 \times 4$ concept is given in the following example.

Example: A curve of $\mathrm{P}_{20} / \mathrm{W}$ versus bd was produced by solving for bd in the equation $\frac{\mathrm{W}}{\operatorname{CIbd} \Delta^{0.5}}=\mathrm{V}_{3}$, where $\mathrm{P}_{20} / \mathrm{W}$ and $V_{3}$ are the coordinates of arbitrary points on the curve shown in fig. 4. For instance, at $\mathrm{P} / \mathrm{W}=0.1$, the value of $\frac{W}{C I b d \Delta^{0.5}}$ is $0.311\left(V_{3}\right)$ and bd $=\frac{15,000 / 4}{7 \times 0.5 \times 0.311}=3440$. This point $(0.1,3440)$ then becomes a point on the curve $P_{20} / \mathrm{W}$ versus bd in fig. 6. Next, a curve of $\mathrm{P}_{\mathrm{T}} / \mathrm{W}$ versus bd was produced in a similar manner (fig. 6). The intersection of these curves in fig. 6 provides a value for bd of 3780 to satisfy the assigned condition.

This procedure, with adjustments made for the assumed motion resistance, was repeated for the other wheeled concepts considered. The respective hyperbolas that describe the tire sizes required for maneuvering for wheeled vehicles are shown in fig. 7 .

ILI SOIL VAIUE SYSTEM

Because of the limited time available in the exercise, a simplified version (4) of the IIL soil value system was employed to determine the tire and track dimensions that would meet the stipulated conditions. At a later date, however, the results were checked against the results of a more complex computerized program. In the simplified version, the effects of tire 
and track slip and tire deformation on vehicle sinkage (and thus on motion resistance) and traction were neglected by the relations used.

To obtain LII soil values that were comparable to a soil with an RCI of 7 , the method developed by LIL for conversion of soil values to cone index was used. The soil selected by applying this method was. LII soil No. 6 which has the following values:

$$
\begin{aligned}
c(\text { cohesion }) & =0.82 \mathrm{lb} / \mathrm{in} .^{2} \\
k_{c} & =2.2 \mathrm{lb} / \mathrm{in} .^{\mathrm{n}+1} \\
k_{\phi} & =1 \mathrm{lb} / \mathrm{in}^{\mathrm{n}+2} \\
\mathrm{k}_{\mathrm{b}} & =1 \text { (dimensionless) } \\
\mathrm{k}_{\theta} & =1 \text { (dimensionless) } \\
\mathrm{n} & =0.35 \text { (dimensionless) } \\
\gamma(\text { soil density) } & =0.06 \mathrm{lb} / \text { in }^{3} \\
\varnothing \text { (angle of internal friction) } & =19.7 \mathrm{deg}
\end{aligned}
$$

ANAIYSIS TECHNIQUES - Vehicle sinkage was considered the limiting criterion in the selection of adequate tire and track sizes. The analysis procedure adopted was to assign several arbitrary levéls of sinkage and compute the dimensions of the tire or track that would yield the selected value of sinkage. The maximum values of sinkage were taken as a sinkage equal to one-third the wheel diameter for wheeled vehicles and 15 in. for the tracked vehicle. Once wheel or track dimensions were established, it was possible to determine values of tractive effort, motion resistance, and drawbar pull. If the drawbar pull was negative, another value of sinkage was assumed and the process repeated until the drawbar pull value was positive. Tire sizes selected on the basis of AMRB calculations were 
employed in the proper equations to determine whether they yielded reasonable values of sinkage and drawbar pull. Curves relating the appropriate parameters were drawn. For a given wheel width and load, curves were drawn for tire diameter versus traction $(H)$, bulldozing resistance $\left(R_{b}\right)$, compaction resistance $\left(R_{c}\right)$, and sinkage $(Z)$. Curves were drawn for track width versus length for several sinkages in the assumed soil and for $R_{T} / W$, $\mathrm{DP} / \mathrm{W}$, and $\mathrm{H} / \mathrm{W}$ versus track width.

Sinkage - Sinkage (Z) in inches was computed for a wheel (rigid) from the equation

$$
z=\left[\frac{3 W}{b k \sqrt{D}(3-n)}\right]^{\frac{2}{2 n+1}}
$$

and for a track from the equation

$$
Z=\left[\frac{(n+I) W}{A k}\right]^{1 / n}
$$

where

$$
\begin{aligned}
& A=\text { area, sq in.; for a track, } A=b l \\
& b=\text { wheel or track width, in. } \\
& D=\text { wheel diameter, in. } \\
& k=\frac{k_{c}}{b}+k_{\phi} ; k, k_{c}, \text { and } k_{\varnothing} \text { are soil values } \\
& \ell=\text { track length, in. } \\
& n=\text { soil value } \\
& \mathrm{W}=\text { wheel or track load, lb }
\end{aligned}
$$

Motion Resistance - Total motion resistance $\left(R_{T}\right)$ in pounds is the sum of motion resistance caused by compaction $\left(R_{c}\right)$ and motion resistance caused by bulldozing $\left(R_{b}\right)$ where 


$$
\begin{aligned}
R_{c} & =\frac{b k}{(n+l)} z^{n+1} \\
R_{b} & =b\left(2 Z c K_{b}+\gamma z^{2} K_{\theta}\right) \\
c & =\text { cohesion, } I b / i n .^{2} \\
\gamma & =\text { soil density, lb/in. }{ }^{3}
\end{aligned}
$$

$\mathrm{K}_{\mathrm{b}}$ and $\mathrm{K}_{\theta}$ are parameters related to the Terzaghi bearing capacity factors

Traction - Total traction (H) in pounds is the total horizontal thrust developed by a track or wheel and includes both net thrust (drawbar pull) and motion resistance. It'is determined from the equation:

$$
\mathrm{H}=\mathrm{Ac}+\mathrm{W} \tan \varnothing
$$

where

$\mathrm{A}=$ area, sq in.; for a wheel, $\mathrm{A}=\mathrm{b} \sqrt{(\mathrm{D}-\mathrm{Z}) \mathrm{Z}}$

$\phi=$ angle of internal friction

Drawbar Pull - Drawbar pull (DP) is the difference between traction and motion resistance and is computed according to the equation $\mathrm{DP}=\mathrm{H}-\mathrm{R}_{\mathrm{T}}$.

WHEELED CONCEPIS - Procedures for determining the adequacy of tire sizes for one-pass straight-line operation are illustrated in the following example, using the 10x10 concept with $42 \times 40$ tires. Curves developed for the following relations for a given wheel width ( $40 \mathrm{in.}$ ) and load ( $1500 \mathrm{lb}$ ) are given in fig. 8 .

\section{Sinkage -}

$$
z=\left[\frac{3 W}{b k \sqrt{D}(3-n)}\right]^{\frac{2}{2 n+1}}=\left[\frac{3(1500)}{40(1.06) \sqrt{42(2.64)}}\right]^{\frac{2}{1.7}}=8.6 \mathrm{in} .
$$


Since the calculated sinkage is less than $\frac{D}{3}=\frac{42 \mathrm{in} .}{3}=14.0$ in., the design meets the sinkage criterion.

Motion Resistance -

$$
\begin{aligned}
& R_{c}=\frac{b k}{n+I} z^{n+1}=\frac{40(1.06)}{1.35}(8.6)^{1.35}=570 \mathrm{Ib} \\
& R_{b}=b\left(2 Z c K_{b}+\gamma z^{2} K_{\theta}\right)=40\left[2(8.6)(0.82)(I)+0.06(8.6)^{2}(1)\right]=740 \mathrm{Ib}
\end{aligned}
$$

Traction Per Wheel -

$$
\begin{aligned}
& H=A c+W \tan \phi=[b \sqrt{(D-Z) Z}(c)]+W \tan \phi \\
& H=[40 \sqrt{(42-8.6) 8.6}(0.82)]+1500(0.358)=1090 \mathrm{lb}
\end{aligned}
$$

Drawbar Pull - Assuming buldozing resistance only for leading wheels and full compaction resistance for all wheels, motion resistance $=2\left(5 \mathrm{R}_{\mathrm{c}}+\mathrm{R}_{\mathrm{b}}\right)=2[5(570)+740]=7180 \mathrm{Ib}$, and tractive effort $=10 \mathrm{H}$ $=10(1090)=10,900 \mathrm{lb}$. Drawbar pull $=$ tractive effort - motion resistance $=10,900-7180=3720 \mathrm{Ib}$.

Maneuver - The 10xio configuration with $42 \times 40$ tires will produce a drawbar pull of $3720 \mathrm{lb}$ while operating in a straight line on the specified soil and sinking 8.6 in. Because the $10 \times 10$ is considered to be "a wheeled vehicle designed for close tracking of front and rear units," any finite positive drawbar pull is sufficient to permit maneuvering. Thus the 10x10 configuration is an acceptable design.

TRACKED CONCEPTS - The following sample calculations illustrate the technique employed in determining track sizes. Curves for the pertinent relations resulting from the following computations are given in figs. 9, 10 , and 11 . 
Solving for Track Length, $\ell$ - Assuming sinkage of $15 \mathrm{in}$. and a track width of 22 in., solving for $\ell$ in the soil specified above (considering 15,000-Ib gross weight of vehicle, the load per track would be 7500 lb):

$$
l=\frac{(n+1) W}{b k z^{n}}=\frac{1.35(7500)}{22(1.1)(15)^{0.35}}=162 \mathrm{in.}
$$

Motion Resistance - Compute motion resistance as follows:

$$
\begin{aligned}
& R_{c}=\frac{b k}{n+1} z^{n+1}=\frac{22(1.1)}{1.35} 15^{1.35}=6951 b \\
& R_{b}=b\left(2 Z c K_{b}+\gamma z^{2} K_{\theta}\right)=22\left[2(15)(0.82)(1)+0.06(15)^{2}(1)\right]=8381 b \\
& R_{T}=R_{c}+R_{b}=695+838=15331 b
\end{aligned}
$$

Drawbar Pull - Use the equation $\mathrm{H}=\mathrm{Ac}+\mathrm{W}$ tan $\varnothing$ to compute traction. $H=22(162)(0.82)+7500(0.358)=56101 b$. Drawbar pull, $D B=H-R_{T}$ $=5610-1533=40771 \mathrm{~b}$ (per track).

Maneuver - A 15,000-Ib gross weight vehicle with two tracks each 22 in. wide and $162 \mathrm{in.} \mathrm{long} \mathrm{would} \mathrm{operate} \mathrm{on} \mathrm{the} \mathrm{specified} \mathrm{soil} \mathrm{at} \mathrm{the}$ maximum allowable sinkage, 15 in., with more than 8000 lb of drawbar pull, or a drawbar pull/load $\left(\frac{D P}{W}\right)$ ratio of approximately 0.54 . Because an articulated tracked vehicle was selected for the vehicle configuration and since it was assumed that no additional traction was required to maneuver for articulated tracked vehicles, the excess drawbar pull is sufficient to permit maneuvering.

PROPOSED VEHICLE CONCEPTS

Both the AMRB and III techniques provide the means of determining a 
number of theoretically adequate tire and track dimensions for a given weight vehicle to attain a given level of performance on a given soil condition. After the size of tire required to meet specified performance was established, the tires were selected from commercial stock sizes. In selecting the tires, mechanical efficiency was sacrificed to provide a minimum height of the cargo bed and a low silhouette.

Selected tire dimensions for the $8 \times 8$ and $10 x 10$ concepts are shown against a background of the possible tire dimensions that are theoretically adequate, according to AMRB calculations, in figs. 2, 5, and 7. Note that in all cases the selected sizes are larger than actually required. For instance, from fig. 2 it is apparent that the tire size selected for the $10 \times 10$ concept would have been adequate even on a $6 \times 6$ configuration. The tire sizes selected also are larger than those actually required according to LLI calculations, since the drawbar pulls they provided (2290 Ib in the case of the $10 x 10$ concept and approximately 3000 lb in the case of the $8 \times 8$ concept) were of considerable magnitude.

The track dimensions likewise were taken larger than required to provide a track configuration that was satisfactory from the viewpoints of steering, vehicle stability, and vehicle form and at the same time give a factor of safety from the soft-ground-crossing standpoint. The selected track dimensions can be compared readily with possible dimensions in fig. 3 (AMRB) and figs. 9, 10, and 11 (ILI).

WHEEIED CONCEPIS - The wheeled concepts finally selected were $8 \times 8$ and $10 \times 10$ configurations.

8x8 Configuration - The proposed $8 \times 8$ configuration is shown in fig. 12 . It is a three-unit, articulated wheeled machine equipped with 53×37-10 
Terra-Tires. The three units consist of the control unit, the cargo area, and the engine unit. The dimensions of the vehicle are: length, 28-1/2 ft; width, $9 \mathrm{ft}$; and height, $9 \mathrm{ft} 4 \mathrm{in}$. The ground clearance is taken as 18 in. Maximum flexibility is provided by two fully articulated joints. The joint design incorporates an "inching" system wherein two units may remain stationary while they push or pull the third unit, thus providing a capability of negotiating extremely weak soil. In addition, the joint has a positive lock capability in pitch as well as pitch control so that the second unit can raise the front unit and increase the ability to negotiate vertical obstacles. The rigid locking feature will be of considerable advantage in permitting crossing of ditches by a cantilevering technique; the inching system will permit the vehicle to recover itself from many immobilizations caused by soft soil conditions; and the positive pitch control will facilitate the crossing of many obstacles so that the penalty of the articulated joint is largely compensated for by incorporation of the additional features of the multiunit configuration.

10x10 Configuration - The proposed 10xl0 configuration is show in fig. 13. The vehicle uses 42x40-10 Terra-Tires and has the following dimensions: length, 24 ft 4 in.; width, 9 ft; and height, 7 ft 10 in. Because of the relatively small-diameter tires, the ground clearance is limited to $15 \mathrm{in.}$, but the large tires produce only $8.6 \mathrm{in}$. of sinkage in the selected soil conditions so that the ground clearance can be considered fully adequate from a soft soil viewpoint. The vehicle has two units consisting of the cargo unit, and the engine and cab unit. The special features of the joint described for the $8 \times 8$ concept also are proposed for the $10 \times 10$ configuration. The vehicle is steered by control of the interunit 
joint, precisely as though it were an articulated tracked vehicle.

Comparison of the Wheeled Concepts - From a dimensions standpoint, the $10 \times 10$ concept is preferred to the $8 \times 8$ because it is shorter and lower than the $8 \times 8$ but provides the same cargo space, even though the width of each concept is the same. In regard to sort soil performance, the main criterion in this analysis, the $10 x 70$ is slightly superior to the $8 \times 8$. This may be seen, at least qualitatively, by comparing the positions of the points representing the tire sizes used in the $10 \times 10$ and $8 \times 8$ concepts, respectively, relative to the $6 x 6$ curve in figs. 2, 5, and 7. The superiority of the $10 \times 10$ over the $8 \times 8$ in size and soft ground performance was not gained, however, without penalties. The wider tires used on the $10 \times 10$ will undoubtedly wear faster on the highway and will require higher steering forces. (Both vehicle concepts will demand power steering.) However, the $8 \times 8$ concept will have a considerable advantage over the two-unit $10 x 10$ in maneuvering, in obstacle crossing, and in operating in off-road terrain that has combined geometric and soil obstacles because the additional flexibility of the three-unit configuration will allow it to conform to'the terrain exceptionally well. Both vehicles should provide satisfactory ride on roads and highways because of the suspension system and damping between units.

TRACKED CONCEPT - The proposed track concept is show in fig. 14. It is 28 ft long, 8 ft wide, and 8 it high, and has a ground clearance of 15 in. In elevation, at least, the tracked configuration is very similar to the 10x10 wheeled concept. Since their weights are the same and their soft ground performances are theoretically very similar, they should provide an excellent pair of vehicles for comparison purposes to provide 
additional answers to repeatedly asked questions concerning performance of wheels versus tracks. The concept is an articulated tracked vehicle having freedom in pitch, roll, and yaw. The positive pitch control, cantilevering action, and inching system also are incorporated in this concept. The track size selected was $22 \mathrm{in.}$ wide by $165 \mathrm{in.}$ long. The track contact length of the front unit is $66 \mathrm{in}$. and that of the rear unit is 99 in. This develops a nominal ground pressure of 2 psi, which is approximately equal to that of the M29C weasel. The size of track required to operate in the specified soil could easily have been mounted on a conventional tracked vehicle. However, the repeatedly demonstrated advantages of articulation indicate that this form of vehicle should be used whenever possible. Even though the resulting machine is larger than the equivalent conventional vehicle, the increase in performance should far outweigh the disadvantages.

CONCLUSIONS AND RECOMNENDATIONS

It was concluded that the proposed vehicle design concepts were responsive to the soft soil requirements specified; that the soil-vehicle relations developed by LII and WES could be used with confidence in the selection of appropriate running gear configurations; and that while WES and ILL methods of design differ in detail, they yielded compatible design results. It was recommended that the three vehicle design concepts be fabricated and tested against the design and other environments to determine the adequacy of the design. 
FUTURE PLANS

Funds were obligated to design and fabricate the vehicle concepts proposed, and Clark Equipment Co. was awarded the contract to do the work. The vehicles have been fabricated and are currently undergoing preliminary acceptance tests. A plan of testing incorporating the effects of several environmental factors on vehicle performance has been developed, and the vehicles will undergo tests in accordance with the designed program in the very near future. 
1. U. S. Army Engineer Waterways Experiment Station, CE, "Vicksburg Mobility Exercise A, Vehicle Analysis for Remote-Area Operation." Vicksburg, Miss., Miscellaneous Paper No. 4-702, February 1965.

2. U. S. Department of the Army, "Soils Trafficability." Washington, D. C., Technical Bulletin ENG 37, July 1959.

3. U. S. Army Engineer Waterways Experiment Station, CE, "A Dimensional Analysis of the Performance of Pneumatic Tires on Soft Soils," by D. R. Freitag. Vicksburg, Miss., Technical Report No. 3-688, August 1965.

4. Harrison, W. I., and others, "A Soil Value System for Land Locomotion Mechanics." U. S. Department of the Army, OTAC, Land Locomotion Research Branch, Centerline Mich., Research Report No. 5, December 1958. 
1. Mobility index vs vehicle cone index

2. Design curves for wheeled vehicles in fine-grained soil, 50 passes

3. Design curves for tracked vehicles in fine-grained soil, 50 passes

4. Tire performance in fine-grained soil

5. Design curves for wheeled vehicles in fine-grained soil, one pass, no maneuvering required

6. Design curves for $4 \times 4$ wheeled vehicle in fine-grained soil

7. Design curves for wheeled vehicles in fine-grained soil, one pass, maneuvering required

8. Design curves for 40-in.-wide wheel with 1500-1b load in LII soil No. 6

9. Track length vs track width, IJI soiI No. 6

10. $\frac{\mathrm{DP}}{\mathrm{W}}$ and $\frac{\mathrm{H}}{\mathrm{W}}$ vs track width, LLI soil No. 6

11. $\frac{R_{T}}{W}$ vs track width, LIL soil No. 6

12. Artist conception of $8 \times 8$ wheeled concept

13. Artist conception of $10 \times 10$ wheeled concept

14. Artist conception of tracked concept 


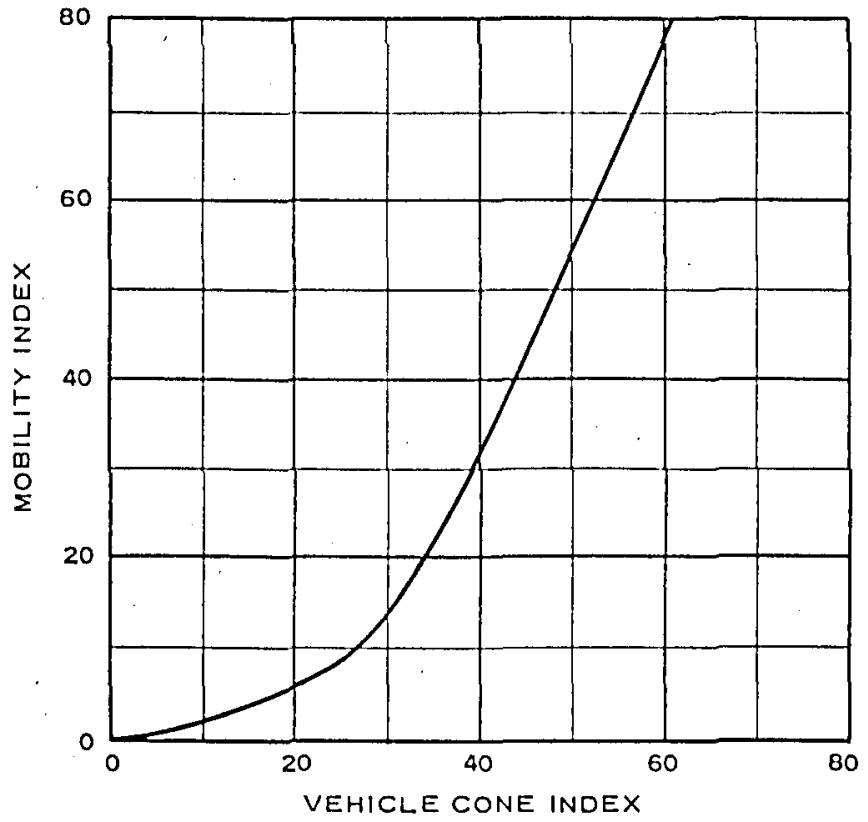

Fig. 1 
Rula, Freitag, and Knight

Fig. I Mobility index vs vehicle cone index 


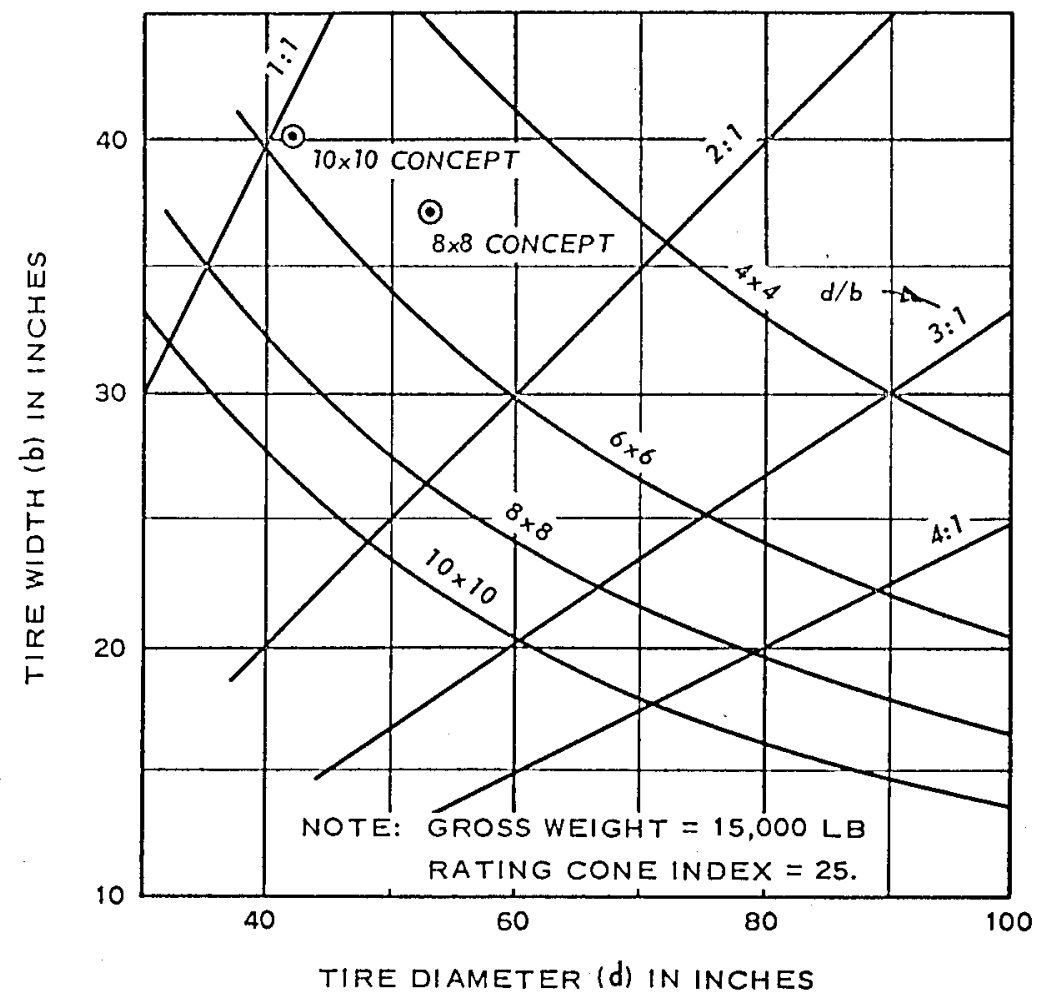


Rula, Freitag, and Knight

Fig. 2 Design curves for wheeled vehicles in fine-grained soil, 50 passes 


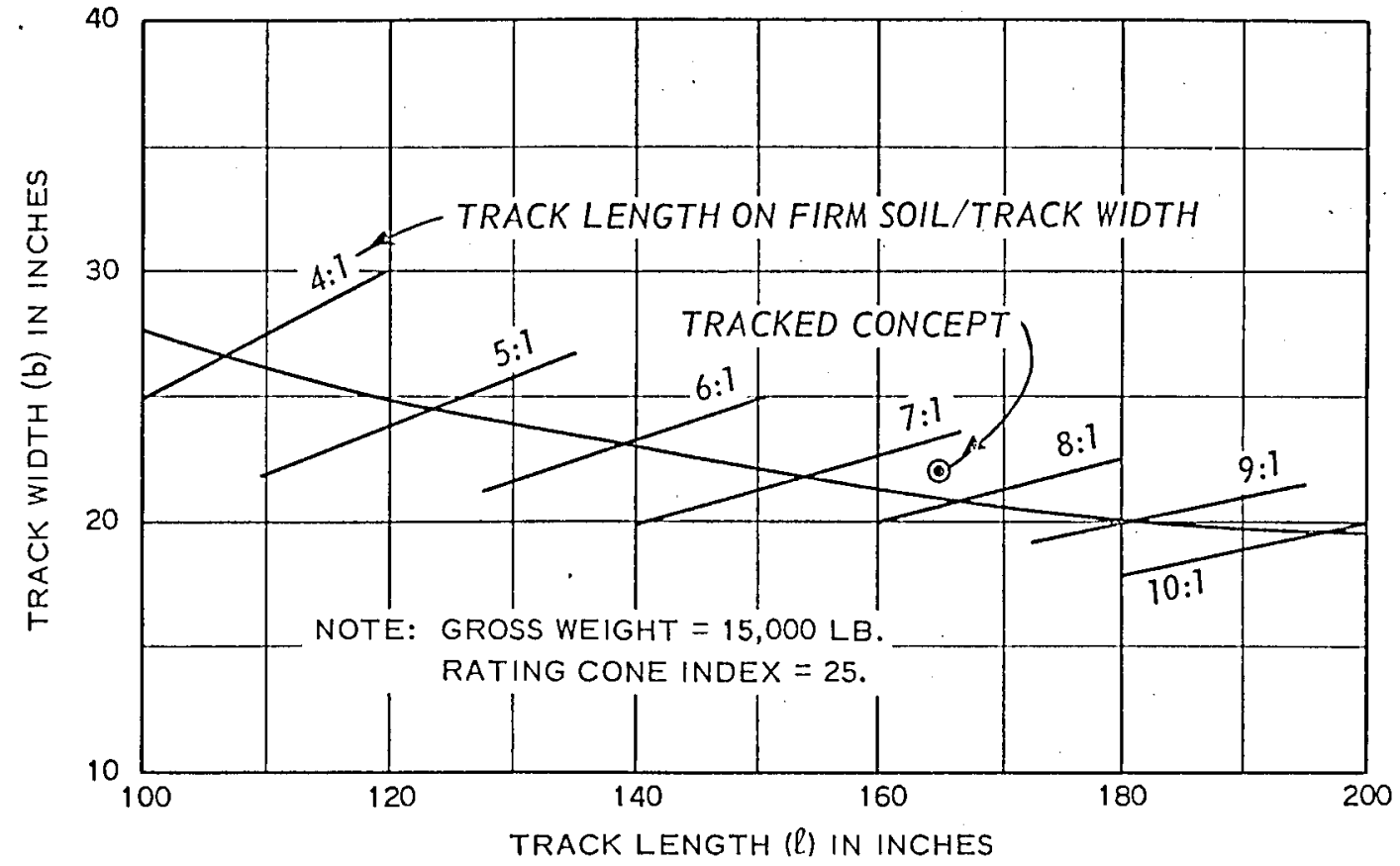


Rula, Freitag, and Knight

Fig. 3 Design curves for tracked vehicles in fine-grained soil, 50 passes 


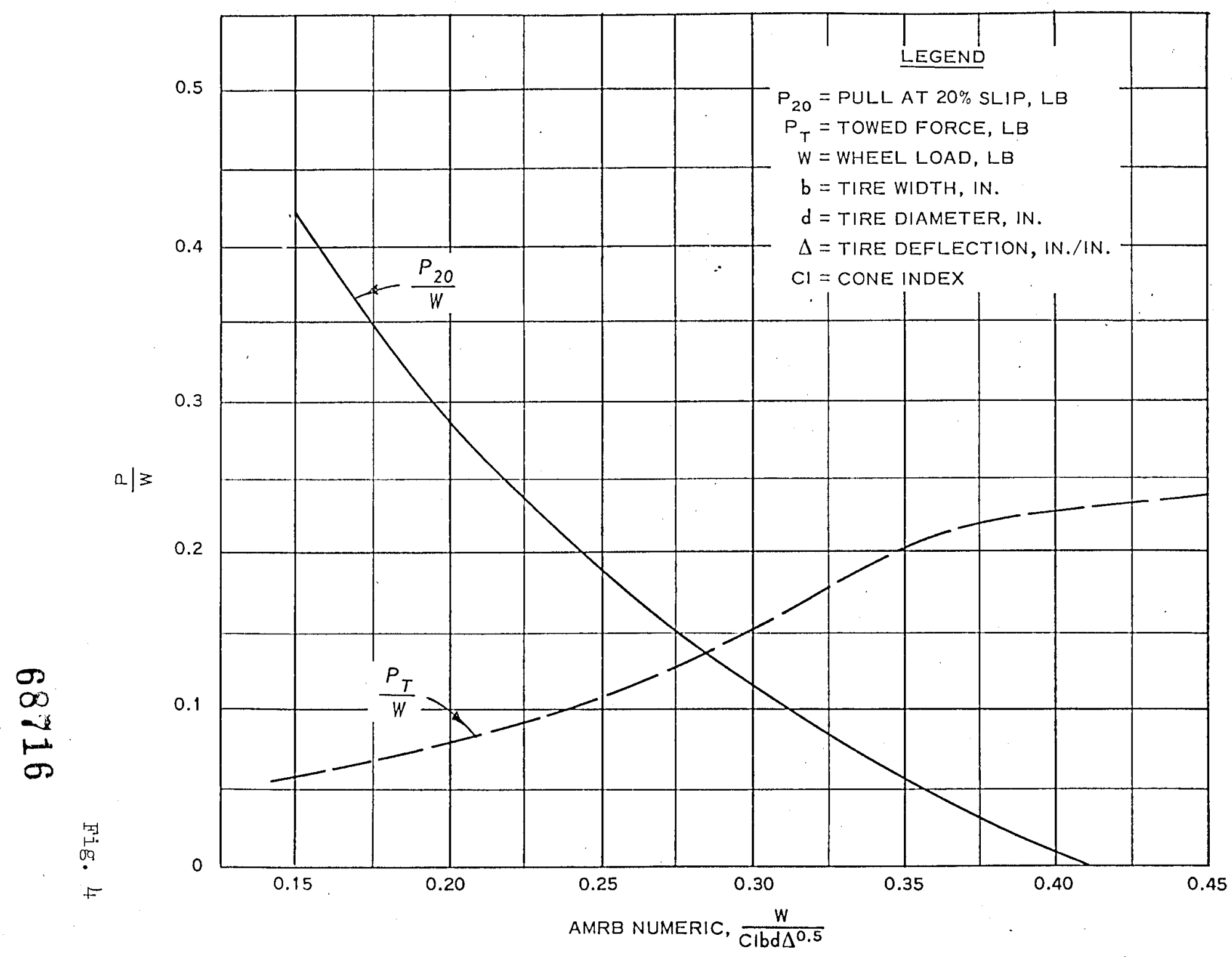


Rula, Freitag, and Knight

Fig. 4 Tire performance in fine-grained soil 


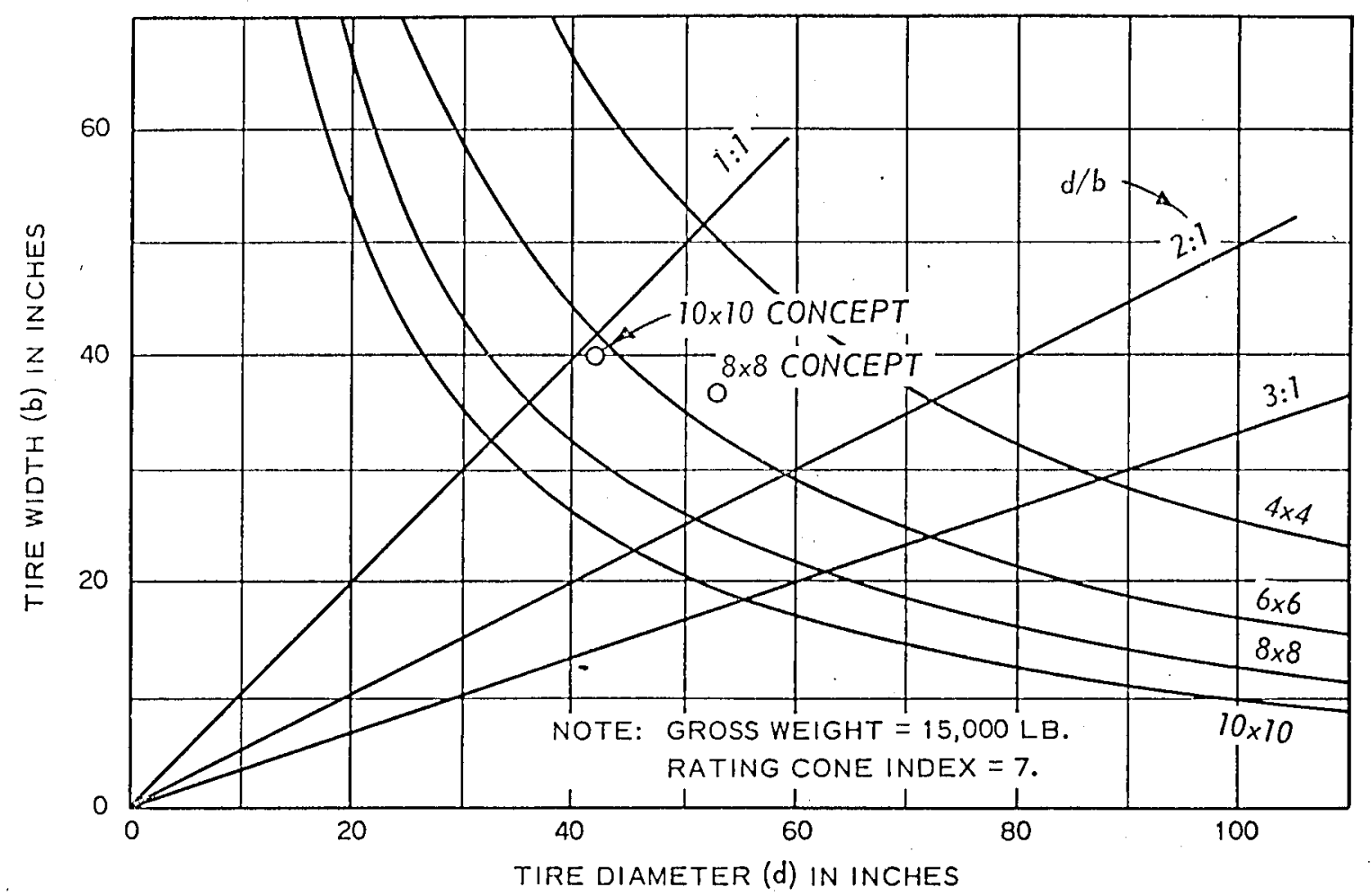


Rula, Freitag, and Knight

Fig. 5 Design curves for wheeled vehicles in fine-grained, soil, one pass, no maneuvering required 


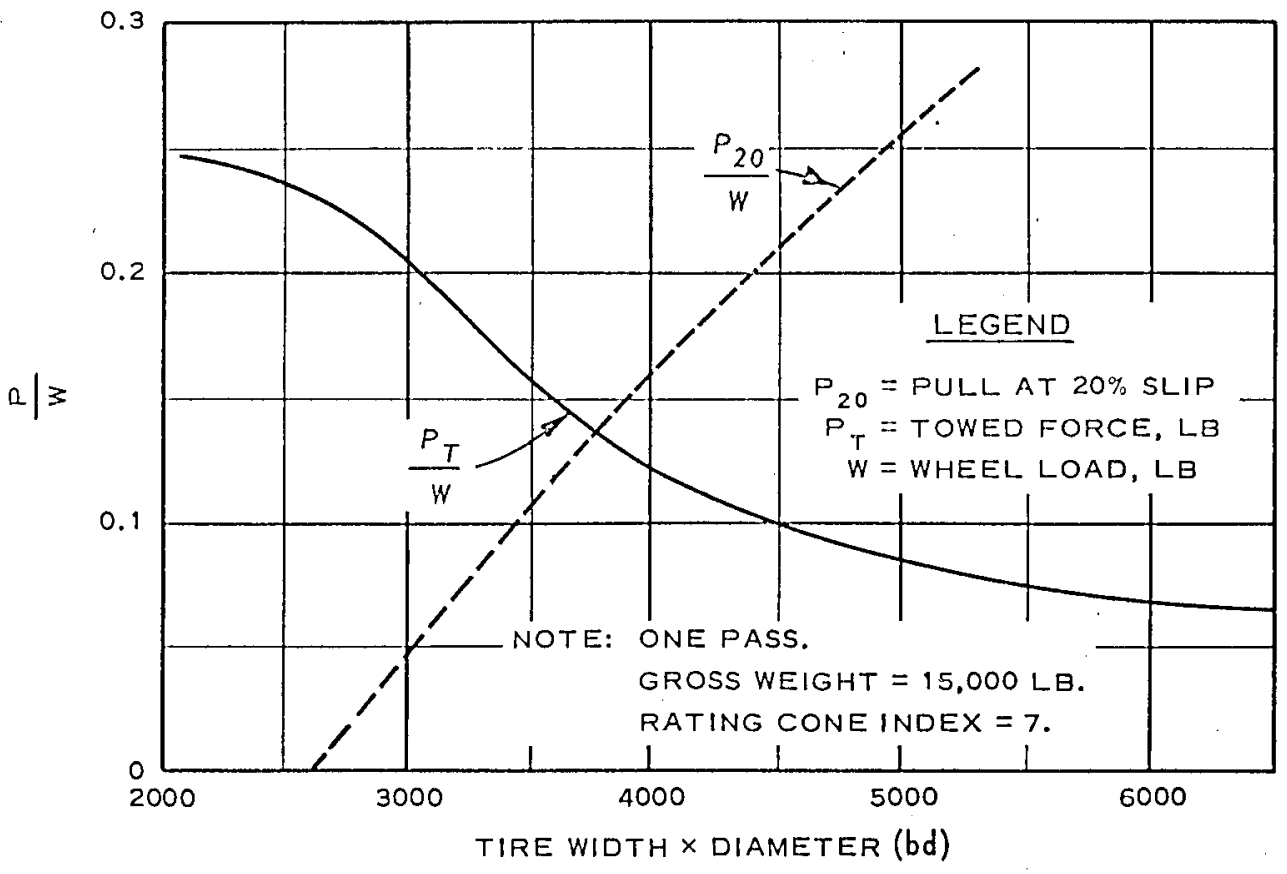


Rula, Freitag, and Knight

Fig. 6 Design curves for $4 \times 4$ wheeled vehicle in fine-grained soil 


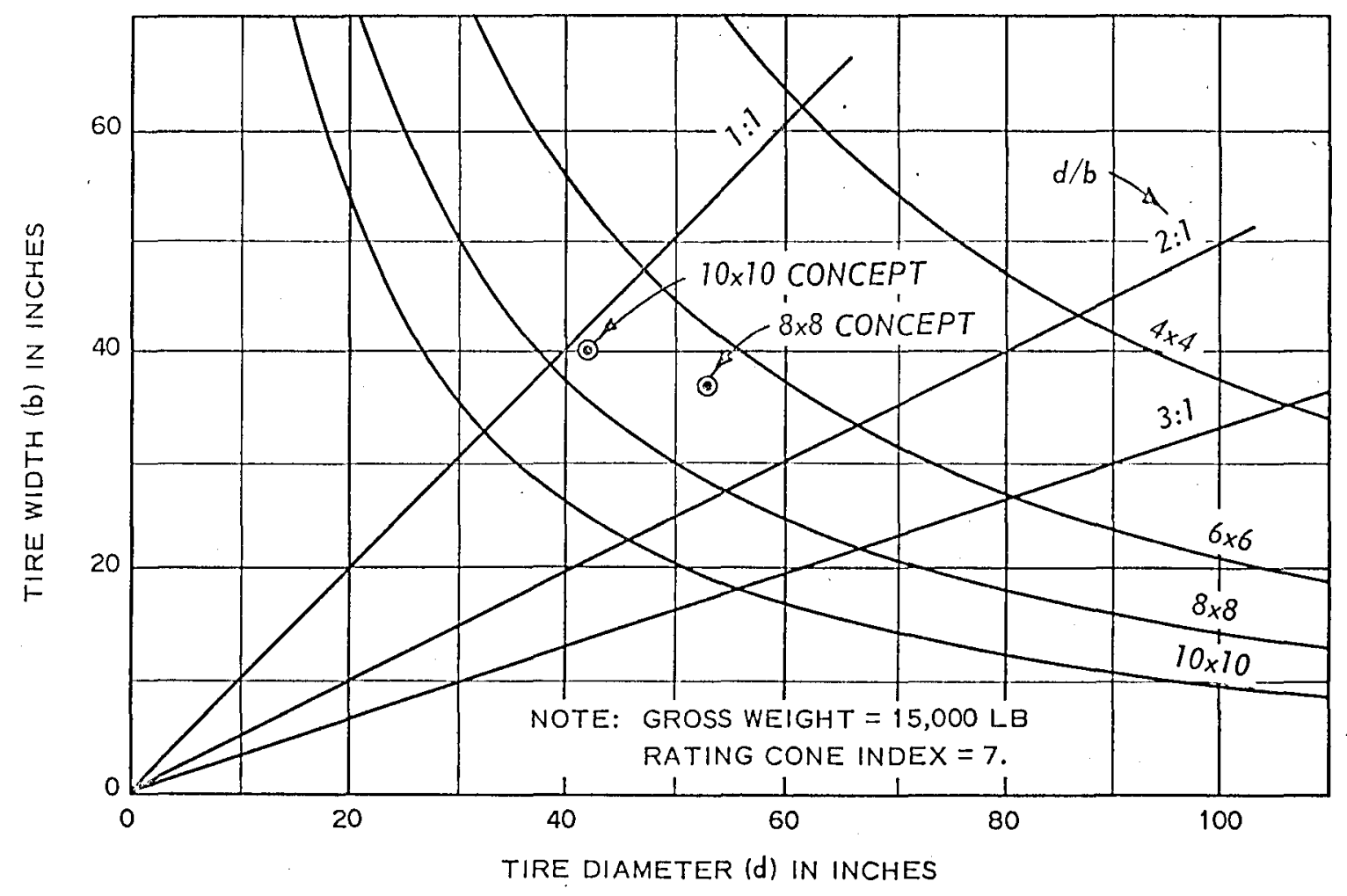


Rula, Freitag, and Knight

Fig. 7 Design curves for wheeled vehicles in fine-grained soil, one pass, maneuvering required 


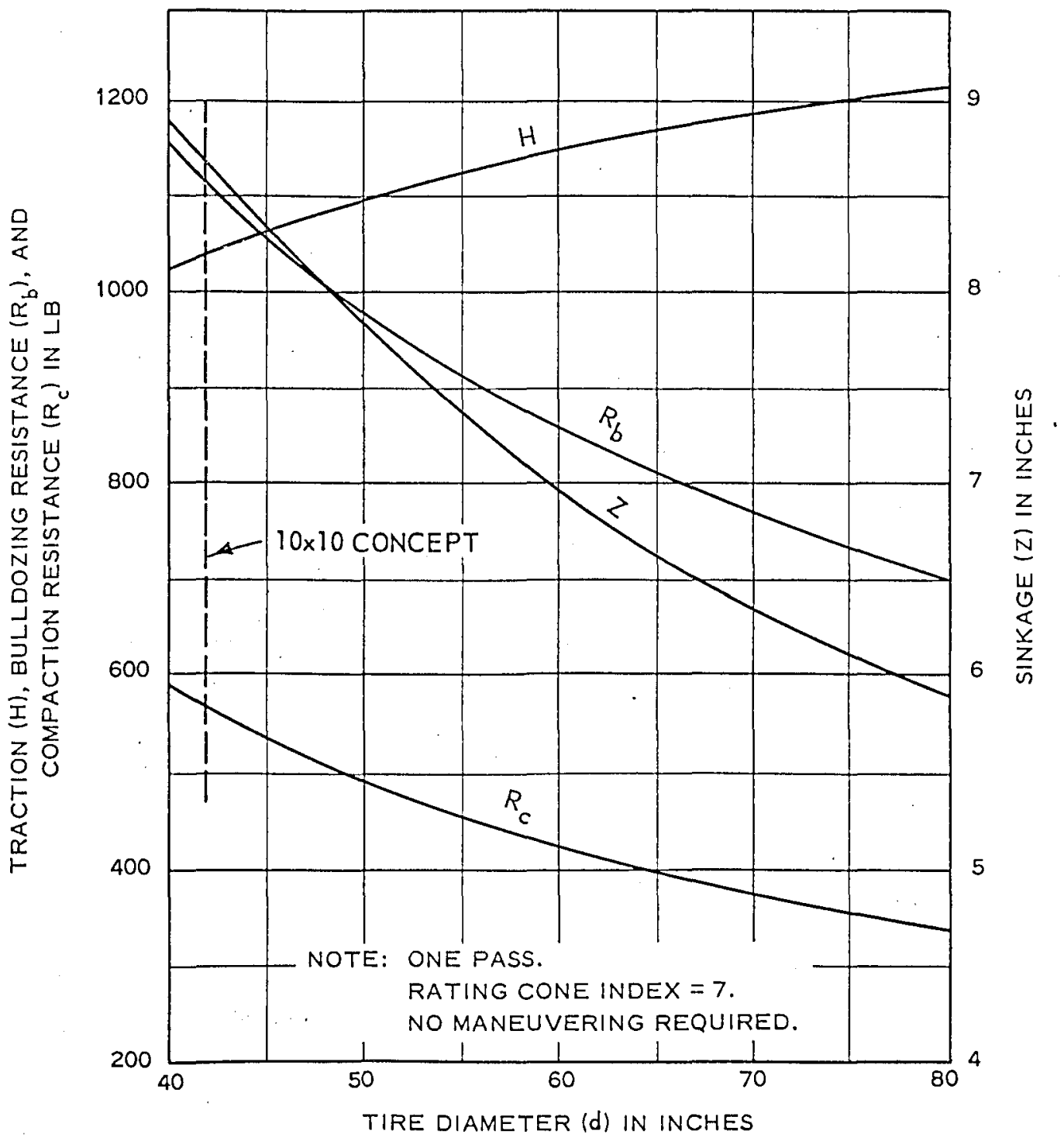

Fig. 8 
Rula, Freitag, and Knight

Fig. 8 Design curves for 40-in.-wide wheel with 1500-Ib load in LLI soil No. 6 


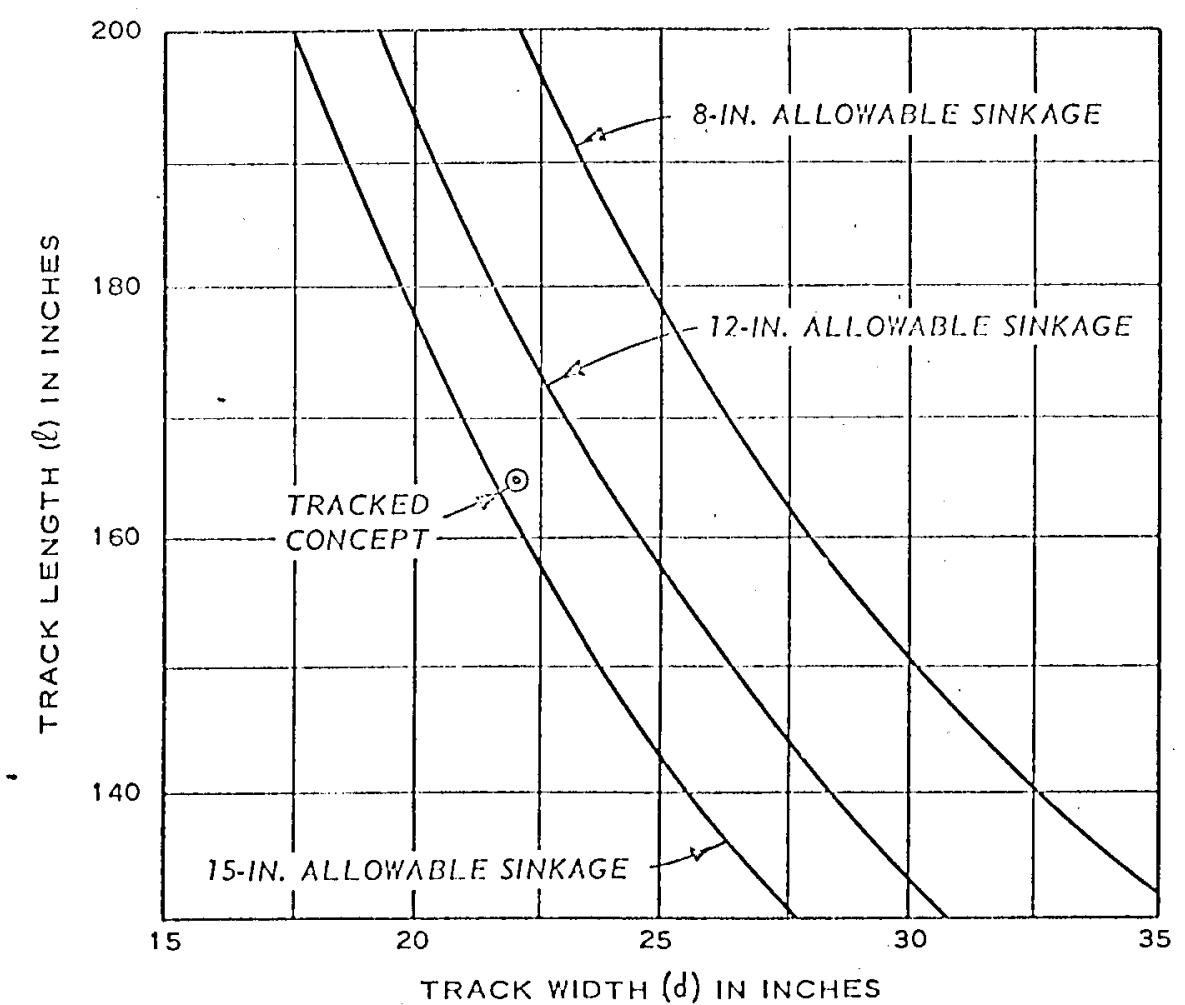


Fula, Freitag, and Knight

Fig. 9 Track length vs track width, LII soil No. 6 


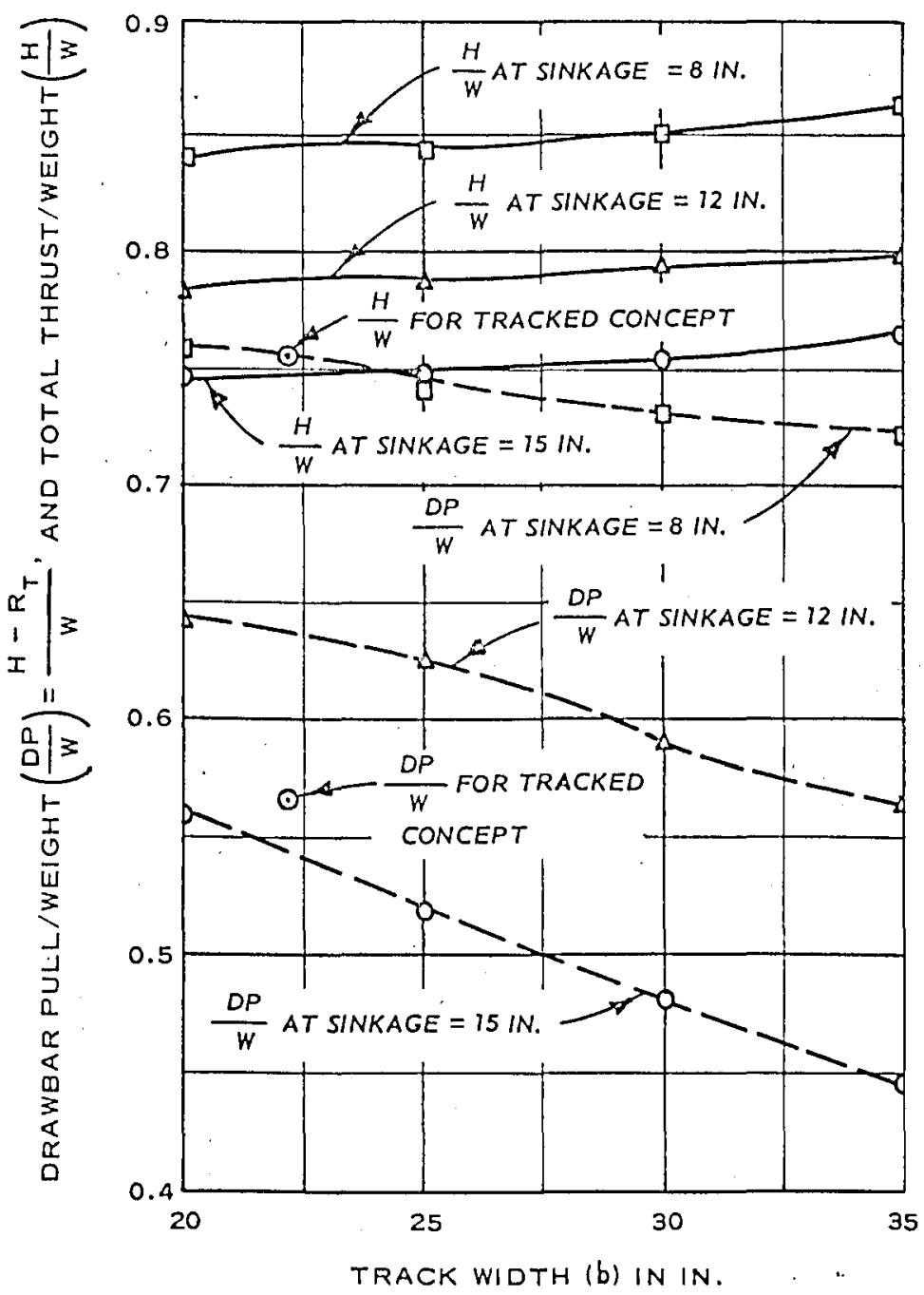

Fig. 10 
Rula, Freitag, and Knight

Fig. $10 \quad \frac{\mathrm{DP}}{\overline{\mathrm{W}}}$ and $\frac{\mathrm{H}}{\overline{\mathrm{W}}}$ vs track width, LLL soil No. 6 


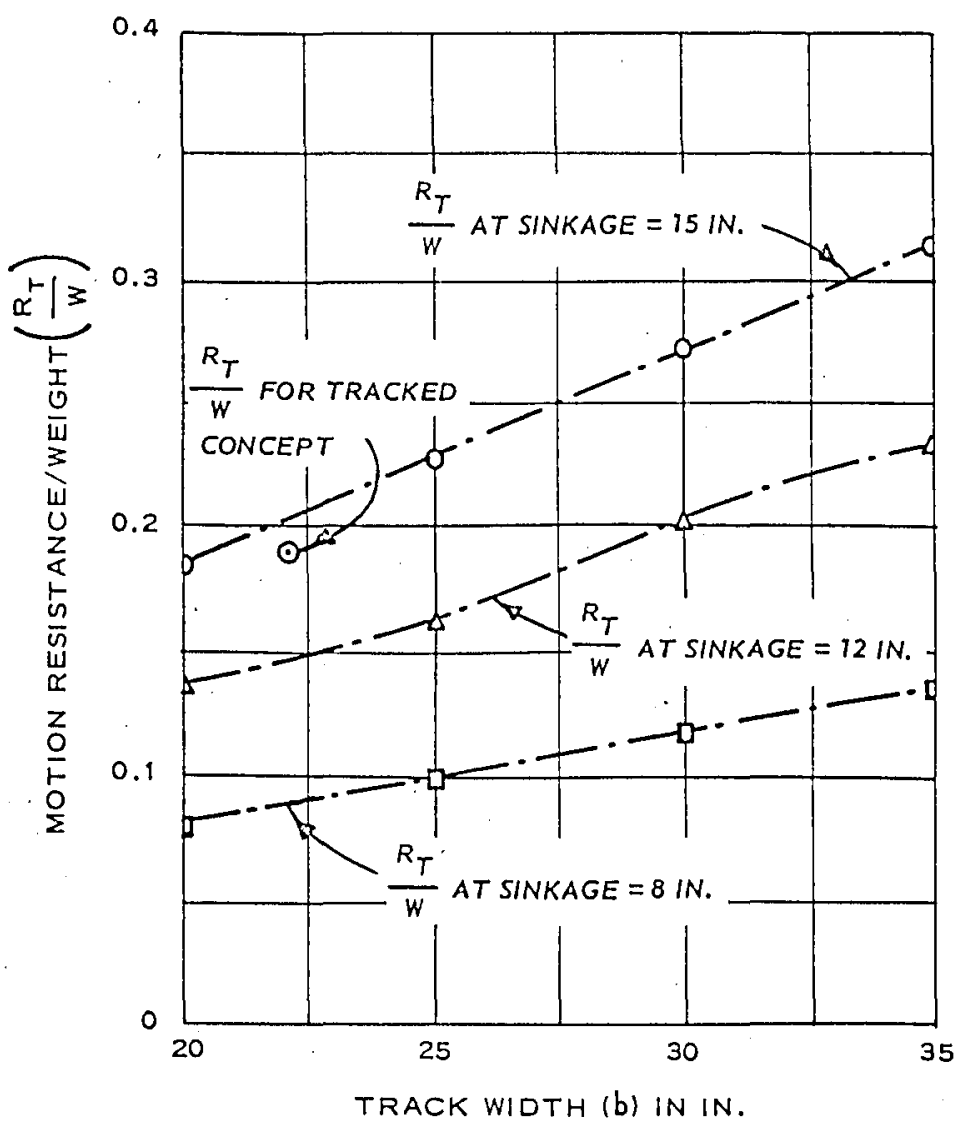

Fig. II 
Rula, Freitag, and Knight

Fig. $11 \frac{\mathrm{R}_{\mathrm{T}}}{\mathrm{W}}$ vs track width, LIL soil No. 6 


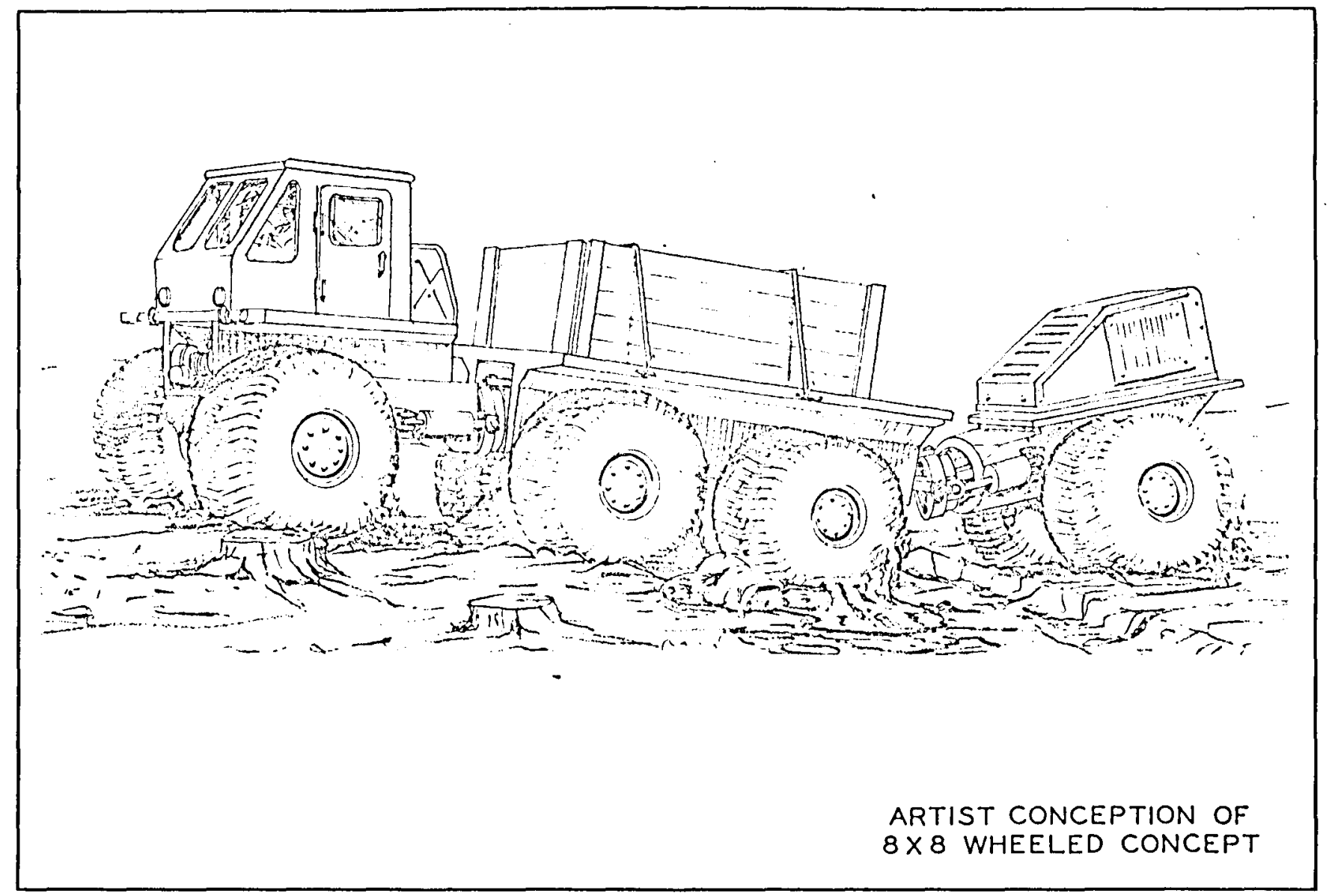


Rula, Freitag, and Knight

Fig. 12 Artist conception of $8 \times 8$ wheeled concept 


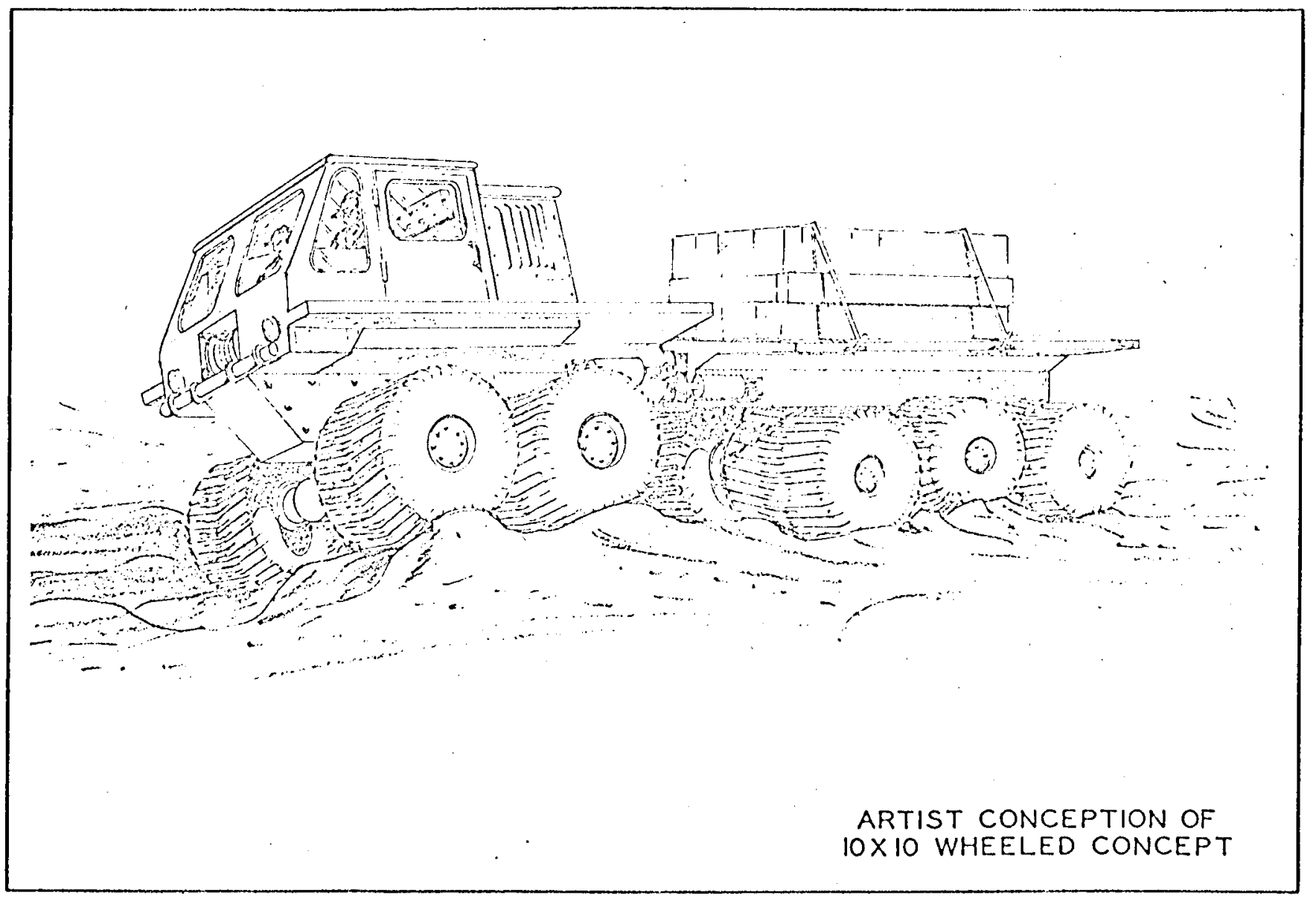


Rula, Freitag, and Knight

Fig. 13 Artist conception of 10x10 wheeled concept 


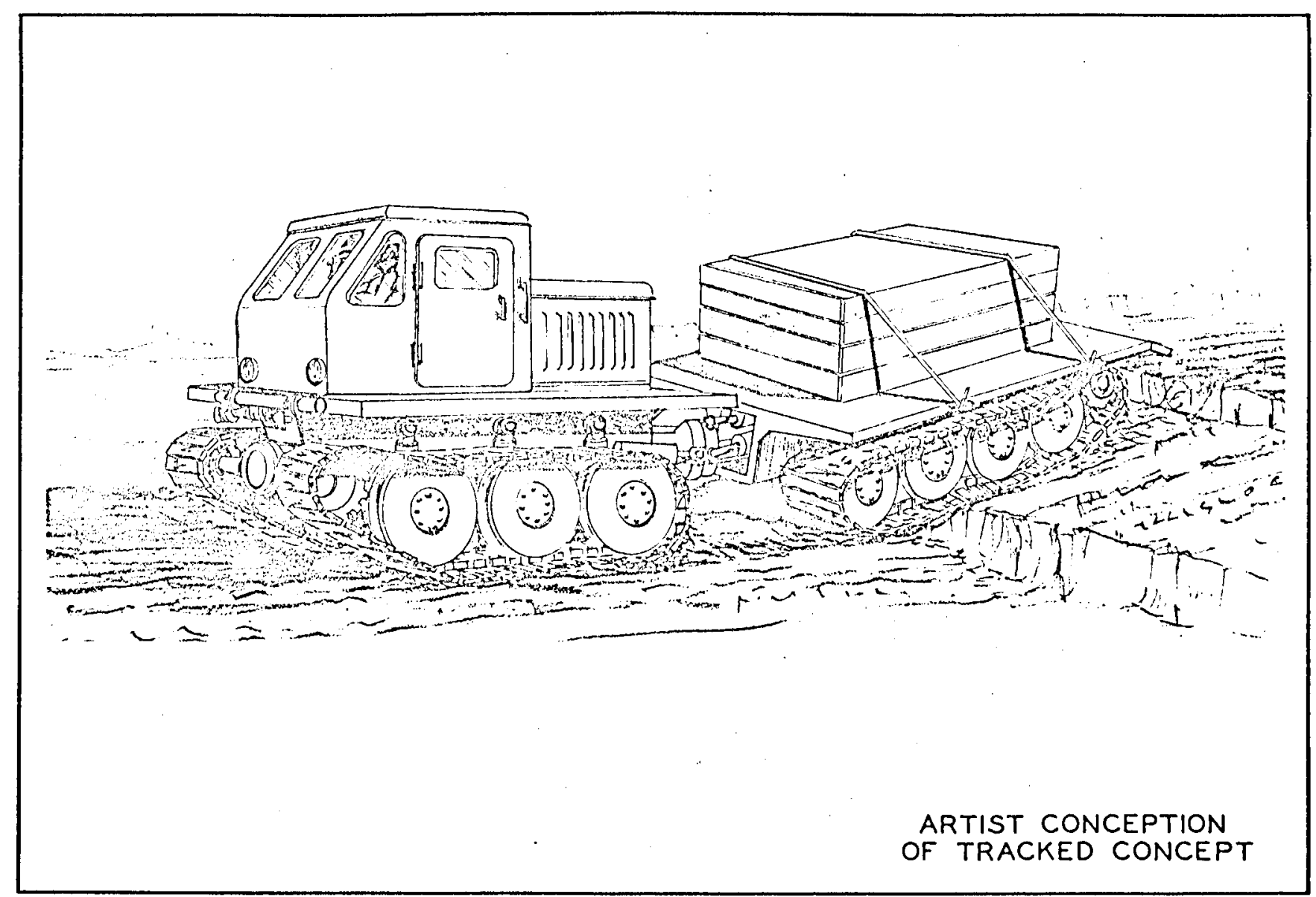


Rula, Freitag, and Knight

Fig. 14 Artist conception of tracked concept 
